Production

ENGINEERING ARCHIVES
2015,Vol. 7, No 2, pp 33-36

ISSN 2353-5156

ISSN 2353-7779 (print version)

(online version)

Article history: $\quad$ Received: 14.01.2015

Accepted: 11.03.2015

Online: 30.04 .2015

Available online on: http://www.qpij.pl

Exist since $4^{\text {rd }}$ quarter 2013

\title{
Evaluation of microbial hazards during creamy cream cheese processing
}

\author{
Joanna Żukowska, Dorota Nowak, Joanna Nowacka, Dorota Miarka \\ Institute of Food Technology and Gastronomy, The State Higher School of Computer Science \& Business Administration, Akademicka 14, \\ Lomza, Poland, e-mail: jzukowska@pwsip.edu.pl
}

\begin{abstract}
The purpose of the work was to identify the potential microbial hazards that may occur during the manufacturing process of creamy cream cheese, and to present the means of their elimination or minimization. The analysis demonstrated that among the most crucial stages that should be particularly monitored are: the quality of raw materials, the control of pasteurization and souring parameters as well as temperature of product packaging, ensuring proper storage conditions of the finished product and hygiene throughout the production. Of these, the most critical step in the entire process (critical control points - CCP) is a heat treatment process which is pasteurization. On the basis of the analysis, it can be concluded that the monitoring of such a process and consistent adherence to Operational Pre-Condition Programs at the thermisation and centrifuging and later packaging, can help guarantee a safe product and its long shelf life.
\end{abstract}

Key words - food safety, quality of food, microbiological hazard

\section{Introduction}

Among many products manufactured from milk, cheeses represent quite an extensive range. There are many types of cheeses, which are classified depending on a variety of milk, texture, fat content, production process and ripening time. In Poland, cheeses are divided according to the content of fat in dry mass. In other countries, there exists a variety of different standards which are connected with local traditions, cheese production norms and climatic conditions. Cheese textures depend on the content of water in them and the technological process. Cheeses are divided into soft and hard varieties.

The aim of the paper is to analyze the possibility of microbiological hazards at each stage of doublecream cheese production from milking and processing of the raw material through production and distribution of the finished product. An attempt will be made to identify hazards essential from the viewpoint of safety food production and assessment of the effects of its potential contamination.

\section{The levels of food safety}

The general principles and requirements of the food law were established by the EU Regulation No. 178/2002 of January 28, 2002. Scientific foundations used for the establishment of the food law are based on the notion of risk and its analysis. The concept of risk is understood as the probability function of negative effects on human health and the severity of these effects as a result of a potential hazard. The hazard is, in turn, a biological, chemical or physical factor in food or feed or the state of food or feed which can cause negative effects on human health. 
The target levels of food safety are defined at country level. Proper levels of protection are the levels recognized by particular countries as appropriate ones for the establishment of sanitary and phyto-sanitary means to protect the lives of people, animals and plants on their territories. The target levels of food safety are closely connected with the target levels of hazards and critical levels established at the level of food manufacturers in compliance with principles of HACCP and Good Practices such as GAP, GVP, GHP, and GMP.

The group of legally established foodstuff microbiological criteria relevant to cheeses determine pathogenic bacteria dangerous to humans. These are Salmonella sp, Listeria monocytogenes, Staphylococcus aureus and Escherichia coli (KOWALIK J. 2011).

\section{The sources or reasons for microbi- ological hazards in milk processing}

Microbiological hazard can come from the raw material, personnel, production halls, air, water, cleaning and disinfection procedures, additives and packaging (KOWALIK J. 2011).

The contamination of milk by original microflora is not high. It constitutes on average a few hundred of bacteria in $\mathrm{cm}^{3}$. The contamination of milk can happen even in the udder in case of a disease, while milking or any other sequential procedures (ZADERNOWSKI M.R. AT AL. 2008)

The necessity to maintain an appropriate level of hand hygiene by food industry personnel results from their frequent direct contact with the processed stock as well as the finished product.

A milk processing plant, cold stores and production halls can be populated by Listeria monocytogenes. The areas where contamination can concentrate and then be introduced into the product are, first of all, all kinds of floors, especially in such places where water can accumulate, for instance, at a packing machine (KOWALIK J. 2011; KRĘGIEL D. 2006).

In production halls there is a typical saprophitic microflora: filamentous fungi of Aspergillus sp., Penicillium, Cladosporium, Rhizopus, Mucom, as well as bacteria of Micrococcus sp., Bacillus, Staphylococcus and other kinds specific to the production. Many factors influence the degree of microbiological contami- nation of the air in a plant (GUTAROWSKA B. 2011; KRĘGIEL D. 2006). It is estimated that more than $25 \%$ of bacteria present in the air comes from people.

The microbiological quality of the used additives in terms of number as well as kinds of present bacteria is extremely varied (BRUŻEWICZ, A. MALICKI A. 2007).

\section{Good Hygiene Practice in a company}

GHP in a company is a definition which includes a few areas closely integrated and directed at the achievement of the optimum goal, which is food safety. The requirements of GHP are often defined by Pre-Condition Programs and cover the following (ZIAJKA S., TARCZYŃSKA S. 2011):

- location, surrounding and infrastructure of a company,

- provision of the appropriate amount of the necessary equipment and machines,

- careful choice of raw materials and feedstocks,

- systematic washing with the use of proper equipment and chemicals,

- provision in water of the proper quality and waste control,

- protection against pests,

- proper storage of foodstuff,

- hygiene of the personnel and personnel training.

\section{Hazards and means of control at par- ticular stages of the process of cream cheese}

Cream cheese is fat cheese of the cottage cheese type and is called cream cheese or double cream cheese.

The raw material for cheese is cow milk which is standardized to $12 \%$ of fat content. The cream flows to a separator where it is heated to $55^{\circ} \mathrm{C}$, homogenized and cooled. The cream at the coagulation temperature at $23-24^{\circ} \mathrm{C}$ is directed to a fermentation tank. After adding milk bacterial cultures and rennet, the process of coagulation takes place, until the product reaches $\mathrm{pH} 4,9-4,7$. The curd is then centrifuged and cooled to the temperature of $8^{\circ} \mathrm{C}$. After that the curd is heated to $80^{\circ} \mathrm{C}$. The separator is set to obtain the dry mass of the product at $35 \%$, and the amount of salt at $0,8 \%$ is 
added. On coming out of the separator the product goes to the agitator/mixer where spices and stabilizers are added. The cooling of the product takes place to obtain a temperature of $8^{\circ} \mathrm{C}$. The storage and distribution should not break the cold chain (TEAM OF DAIRY, 2012). There is a risk of getting bacterial pathogens into milk processing at this stage as raw milk can occasionally contain them. However, the hazard can be controlled by supervising the construction of the milk processing plant (TEAM OF DAIRY, 2012). The means of control over such a risk are the pre-defined conditions of storage: the temperature below $5^{\circ} \mathrm{C}$ and the period of stay in a silo before pasteurization is limited to a minimum (TEAM OF DAIRY, 2012).

Centrifuging and standardization of fat: The means of control at this stage are adherence to the centrifuging temperature parameters, to control the lipase activity and time limitation between standardization and pasteurization.

Pasteurization standardized cream: The means of control over the risks are the fulfilment of the requirements of GHP in reference to equipment and machines.

Cooling; The means of control are the proper washing and rinsing procedures and ensuring the proper functioning of the device.

Heating and homogenization: The hazard at this stage can be a secondary contamination or the impossibility of obtaining the appropriate temperature. The means of control are the proper washing and rinsing procedures and ensuring the proper functioning of the device; monitoring of the temperature.

Filling of the fermentation tank with pasteurized cream poses two following hazards: the improper temperature of the cream - either too cold or too hot for the growth of the acidified culture and the secondary contamination from the improperly cleaned cables and surfaces. Operational Pre-Condition Programs applied at this stage are the proper arrangements of the work of the pasteurizer.

Coagulation is connected with the hazard of contamination of the pasteurized cream by pathogenic bacteria either due to the impossibility of close control of the previous stages of the process or secondary contamination from the equipment or the environment of the company. The means of control over the risk are: adherence to the defined and planned washing proce- dures of the equipment as well as the area of the plant; the use of the active stock culture added a corresponding dose and chosen in such a way that it is resistant to local bacteriophages; establishing hygienic barriers to avoid cross-contamination; monitoring the speed and level of acidity development alongside withdrawal of the batches with the exceeding parameters.

Thermisation: The hazard at this stage can be a secondary contamination from the improperly washed device. The means of control are the proper washing and rinsing procedures.

Flavouring: Operational Pre-Condition Programs comprise specification and audit of the spices at the supplier's to reduce to a minimum their levels of impurity; proper storage of flavourings as well as hygienic treatment of the additives on their way to the agitator and while adding them; implementation of the proper working procedures ensuring their proper dosage.

Agitating: The hazard at this stage can be a secondary contamination from the improperly washed device. The means of control are the proper washing and rinsing procedures.

Packing: The finished product is threatened by the secondary contamination as well as air pollutants while unit batching. The means of control are the proper washing and rinsing procedures and ensuring the packaging materials are properly stored before use assuming that the packaging manufacturer belongs to the authorized suppliers adhering to high hygienic standards.

Storage: Ensuring the proper storage temperature and securing the product against all forms of contamination during the storage period are the means of control.

Distribution: The hazard at this stage is breaking the cold chain.

\section{Evaluation of the Threat to the Con- sumer's Health}

After carrying out the analysis, it is necessary to state that all the analyzed pathogenes may cause inflammatory states of the mammary gland in cows and, as a result, also appear in raw milk. Pasteurization is the main process during the production of cream 
cheese which influences the microbiological security of the finished product. The discussed pathogens may appear in the finished product due to crosscontamination (TEAM OF DAIRY, 2012).

Taking into consideration the acidity $\mathrm{pH}<5,0$ of the finished product, the use of thermisation in combination with the high temperature of centrifuging of the curd as well as packing the product hot and the low number of the pathogenic colonies discussed in the present article and the consequential to human health, their appearance in the finished product can be defined as a medium threat (TEAM OF DAIRY, 2012).

A single consumption of cream cheese or double cream cheese is $60 \mathrm{~g}$. Half of the Polish population buys cheese and cheese spreads at least once a week. Taking into consideration that the symptoms of an illness can manifest at MID $10^{2} \mathrm{jtk} / \mathrm{g}$ of the product, in a usual portion of $60 \mathrm{~g}$ the number of cells will constitute $6 \times 10^{3}$ jtk (TEAM OF DAIRY, 2012). Cream cheese can cause food poisoning. Making a full list of microbiological threats makes it possible to choose proper preventive measures and means of control over specifically identified threats which can appear in the production process.

\section{Summary and conclusions}

The analysis of microbiological hazards in the production process of double cream cheese has shown that there are stages which should be closely supervised so that the finished product is safe. Monitoring the quality of raw material, pasteurization parameters, acidification process, packing temperature, storage conditions of the finished product, and the proper hygiene in the whole production cycle are extremely important.

The process of heat treatment, which is pasteurization, is the stage where the elimination of the pathogens essential for the health safety of the product takes place on condition that temperature parameters and time of holdover in the appropriate temperature are critical points to the whole process (CCP). Monitoring this stage and consistent adherence to Operational PreCondition Programs at the thermisation and centrifuging and later packaging, can guarantee a safe product and its long shelf life.
The analysis of hazards has also shown the vital role of physical workers in the whole process. It indicates a huge need for training the personnel engaged in food production.

Adherence to the requirements of Good Hygienic Practice and the implementation of HACCP systems at each stage of the food chain by each manufacturer co-operating with food industries from primary production to manufacturers of additives and packaging and close co-operation of all links alongside governmental food inspections positively influences production of safe food.

\section{References}

1. BRUŻEWICZ, A. MALICKI A. 2007. Microbiological status of selected spices and survival of microorganisms in them. "Żywność. Nauka. Technologia. Jakość" 4(53), 99-108.

2. KoWALIK J. 2011. Threats: Threats microbiology in the dairy industry. Forum Mleczarskie Biznes 2/2011 http://www.forummleczarskie.pl/ (05.03.2012).

3. KRĘGIEL D. 2006. Microbial contamination of air technology hall and the quality of manufactured packaging. "Żywność. Nauka. Technologia. Jakość" 1 (46), 52-5.

4. Team Of Dairy 2011. Sanitary Hygienic Code. Ed. 6 of 16.09.2011r.

5. TeAm OF DAIRY 2012. Technology Manual IT / 06 Version 4 of 18.01.2012.

6. TEAM OF HACCP 2012. The HACCP plan no. 2 for cream cheese cream „Ostrowia” ed. 9 of 16.01.2012r.

7. TEAM OF DAIRY 2011. Quality specification DT. Cream cheese cream ed. 6 of $19.10 .2011 \mathrm{r}$.

8. ZADERNOWSKI, M.R., ZADERNOWSKA A., OBIEDZIŃSKI, M., ZADERNOWSKI. R. 2008. HACCP Catalog of Biological physical and Chemical Hazards. Gdańsk ODDK.

9. ZiaJKA, S., TARCZYŃSKA, S. 2011. Trends in food safety management. Training materials. Olsztyn. UWM. 